\title{
As mulheres modernas de Pagu em Parque industrial
}

\author{
Tânia Leal ${ }^{1}$ \\ Marcos Paulo Torres Pereira ${ }^{2}$
}

Enviado em: 15/09/2019

Aceito em: 14/11/2019

A literatura brasileira diz muito sobre as relações de poder existentes em nosso país, seja por meio da canonização de certos escritores - em sua maioria homens, brancos e de origem centro-sulista (DALCASTAGNÈ, 2012) -, ou por meio de narrativas sobre realidades que não dizem respeito aos grupos subalternizados ${ }^{3}$ da sociedade. Com as mudanças sociais no Modernismo literário brasileiro, surge a necessidade de questionar como a mulher se encontra nessa realidade de exploração da mão de obra do proletariado e de posses financeiras excessivas da burguesia - realidade que, por certo tempo, continuava ignorada.

Patrícia Galvão, mais conhecida como Pagu, é uma das escritoras que quebra esse paradigma e expõe a realidade das proletárias no contexto de crescimento industrial de São Paulo no início do século XX. Revoltada com o "feminismo pequeno-burguês" e conhecedora da luta de classes - devido à sua participação no Partido Comunista - Pagu tece uma crítica densa em Parque Industrial, que denuncia as relações de poder e os abusos que lhe são imanentes, fazendo o leitor ter noção de que a mulher enfrenta explorações que vão além das questões trabalhistas.

As mulheres que, neste trabalho, denominamos modernast são protagonistas do crescimento da participação feminina no mercado de trabalho ${ }^{5}$. Apesar de a luta de classes já ser debatida no momento em que o Modernismo estava em voga no Brasil, não se levava em conta os recortes necessários para tratar das questões feminino-proletárias. Levando em consideração a iniciativa de Galvão de falar sobre esse tema por meio de seu "romance proletário", analisamos aqui de que forma ser mulher influenciaria nas relações de poder no chão da fábrica, que envolvem lutas de classes e, para esse grupo, questões de gênero.

Com parágrafos em sua maioria curtos e uma narrativa fragmentária, Patrícia Galvão - com o codinome Mara Lobo - ilustra até mesmo na estrutura de sua obra a velocidade exigida pela indústria da época, que já surgia visando o lucro para a burguesia. No entanto, as mulheres trabalhadoras permanecem pobres, com fome, abandonadas, exploradas e diminuídas de diversas formas.

\footnotetext{
${ }^{1}$ Graduada em Letras pela Universidade Federal do Amapá (Unifap); acadêmica pesquisadora do Núcleo de Pesquisas Pós-coloniais (NePC) na linha de pesquisa Pós-colonialismo, discurso e literatura, sob a orientação do Prof. Me. Marcos Paulo T. Pereira.

2 Professor Assistente de Literaturas em Língua Portuguesa pela Universidade Federal do Amapá (UNIFAP). D outorando em Teoria e História Literária pela Universidade Estadual de Campinas. Coordena o grupo de pesquisas Núcleo de Estudos Pós-coloniais (NePC) da Universidade Federal do Amapá. E-mail: marcosptorres1@gmail.com

${ }^{3}$ Empregamos a expressão seguindo o caminho traçado por por Gayatri C. Spivak em Pode o Subalterno Falar.

${ }^{4}$ Os termos em itálico foram empregados para títulos de obra, conceitos operacionais e palavras/expressões que quisemos dar ênfase por sua importância à compreensão do estudo.

${ }_{5}^{5}$ Mercado esse que precisava da mão-de-obra feminina, devido ao crescimento das indústrias no Brasil.
} 


\title{
A questão de gênero no chão da fábrica
}

Beauvoir (1970, p. 10) já dizia que a mulher é sempre vista como o Outro; o homem é o comum, o convencional, o “objeto neutro”. Já a mulher é o diferente, o anormal: "a fêmea é o inessencial perante o essencial. O homem é o Sujeito, o Absoluto; ela é o Outro". Portanto, discutindo-se a realidade dos homens, pensavase que já era incluída toda a sociedade; pensava-se que não se era necessário discutir a realidade da mulher moderna: ela deveria continuar silenciada, tendo seu doloroso cotidiano escondido ao invés de discutido. Em contrapartida, Patrícia Galvão, com sua obra, apresenta uma visão sobre a mulher que a grande maioria não tinha na época: a mulher como protagonista, tendo as questões que envolvem sua realidade como destaque, criticando a forma como as mulheres são tratadas na sociedade moderna.

Apesar de sua importância como escritora moderna e de sua consciência política, Patrícia Galvão teve sua obra por muito tempo esquecida. Por ser mulher e por retratar a realidade de mulheres, Parque Industrial não era tido como uma obra relevante, pois como afirma Michelle Perrot (2001, p. 185),

\begin{abstract}
O "ofício do historiador" é um ofício de homens que escrevem a história no masculino. Os campos que abordam são os da ação e do poder masculinos, mesmo quando anexam novos territórios. Econômica, a história ignora a mulher improdutiva. Social, ela privilegia as classes e negligencia os sexos. Cultura ou "mental", ela fala do "Homem" em geral, tão assexuado quanto a Humanidade. Célebres - piedosas ou escandalosas -, as mulheres alimentam crônicas da "pequena” história, meras coadjuvantes da História!
\end{abstract}

Pagu apresenta em Parque Industrial a problemática do crescimento das indústrias com um recorte de gênero, porém sem unificar a realidade feminina. Letícia Nunes de Moraes, em seu artigo Mulher, raça e classe em Patrícia Galvão e Angela Davis (2017), defende que Galvão forma diversas identidades de mulheres modernas.

As mulheres de Parque Industrial são muito diferentes quanto aos perfis e lugares sociais. Há as militantes, Otávia e Rosinha Lituana, em uma clara referência à Rosa Luxemburgo; há as normalistas: Eleonora se deslumbra com a vida burguesa enquanto Matilde se proletariza; há outras personagens de menor destaque e há Corina, "a mulata do ateliề".

Dessa forma, Pagu explora as realidades femininas, sem se conter a uma só, mostrando que até mesmo se tratando especificamente do gênero feminino, não se deve unificar as realidades sociais. Além disso, Galvão ressalta as diversas formas de ferir a classe trabalhadora feminina que a burguesia consegue atingir, o que abarca não somente a exploração das trabalhadoras, mas muito além - e é nisso que iremos focar.

Glauce Souza Santos (2017), ao falar de Parque Industrial, levanta uma consideração que deve ser feita ao se deparar com a realidade atual: há diversas quebras de paradigmas com a ida da mulher para o mercado de trabalho. Entretanto, apesar de ser uma conquista por muito tempo almejada pelo movimento feminista - e necessária! - não foi suficiente para a busca de identidades narrativas do feminino. Refletindo sobre a igualdade buscada pelo feminismo, defende que é explícita a necessidade não apenas de igualdade, mas de um recorte de gênero perante as necessidades da mulher em uma sociedade patriarcal. Para a autora (SANTOS, 2017, p. 211-212),

A inclusão de mulheres no mundo fabril abriu às mulheres possibilidades existenciais até então bloqueadas, radicalizando a interrogação sobre a relação entre os sexos, mas não dando conta da busca da identidade feminina. (...)

https://periodicos.unifap.br/index.php/letras

Macapá, v. 9, n. 1, $1^{0}$ sem., 2019 
A ordem da sociedade dada às mulheres "seja homem e seja mulher!" fez com que elas passassem da fronteira do mundo dos homens e se conscientizassem a respeito do tropeço da igualdade, pois a igualdade compreendida como integração unilateral no mundo dos homens, não é liberdade.

Pagu mostra que além de enfrentarem os desafios presentes na indústria como a exploração do proletariado e o "encarceramento" dos trabalhadores no local de trabalho - as mulheres tinham que lutar contra problemas relacionados à questão de gênero. Corina, uma das personagens de destaque, é apaixonada por um burguês que ela acredita ser seu futuro marido. Contudo, a quebra da ilusão de Corina chega quando ela se descobre grávida e é abandonada por seu amado, depois de ser expulsa da casa da mãe. Quando se recusa a abortar seu filho, Corina é demitida da fábrica onde trabalha - sua única fonte de renda (GALVÃO, 1933, p. 52): “- Sua safadona! Então, vá se raspando. No meu atelier, há meninas. Não posso mistural-as ${ }^{6}$ com vagabundas".

Desamparada, sem ter dinheiro e abandonada por seu amado - que lhe joga "cem contos" no meio da rua e sai acelerando em seu carro - Corina pensa na morte como solução, mas encontra uma última alternativa como fonte de renda: a prostituição. Assim, além de mostrar as questões da mulher proletária como trabalhadora no chão da fábrica e as dificuldades que surgem com sua ida para o mercado de trabalho, Pagu mostra também que o trabalho tido como "digno" não era possível para todas as mulheres. Ela explicita a dificuldade das mulheres prostitutas diante da obrigação "invisível” de estarem naquele trabalho e de precisarem se submeter a diversos estupros ${ }^{7}$ pagos para conseguir sobreviver. Ali, nos prostíbulos, as mulheres eram diminuídas a apenas objetos sexuais e a mercadorias, pois a partir do momento em que os homens as pagavam para usufruir de sua sexualidade, era como se elas não tivessem mais vontade própria, sonhos, vida. Portanto, ao tecer uma crítica ao sistema, ela critica também o fato de que a liberdade de escolher um emprego não era para todas.

Nas vinte e cinco casas eguaes, nas vinte e cinco portas eguaes, estão vinte e cinco desgraçadas eguaes. Ela se lembra que com as outras costureirinhas, caçoava das mulheres da Rua Ipiranga. Sente uma repugnancia, mas se acovarda. Faz entre lagrimas, como as outras (GALVÃO, 1933, p. 57).

Carmen Sílvia A. de Oliveira (2014, p. 224) defende que em Parque Industrial “a repressão sobre a mulher é refletida na falta de respeito, na repressão e consequente abuso de poder de uma classe sobre a outra, ou seja, entre a burguesia e o proletariado". Na narrativa de Pagu encontram-se diversas demonstrações de humilhação da mulher: a burguesia a trata como mero objeto de consumo, como se ela devesse estar ali apenas para o prazer burguêsmasculino - seja esse sexual ou financeiro, conquistado por meio do trabalho das proletárias, que trabalhavam para gerar lucro para seus patrões. Dentre tantos momentos da narrativa, a exploração sexual pode ser percebida na "caça" da burguesia (notadamente no bairro proletário) por "carne fresca e nova" (GALVÃO, 1933, p. 42). Em determinado momento, a título de exemplo, burgueses comentam sobre uma moça que lhes chama a atenção, quando um deles enfatiza que apenas a aparência ali é positiva, pois na verdade a moça é uma analfabeta. O outro responde que "Pruma noite, ninguem precisa saber ler" (GALVÃO, 1933, p. 43).

\footnotetext{
${ }^{6}$ Os trechos de Parque Industrial utilizados neste trabalho estão como escritos na edição utilizada como fonte. Portanto, alguns desacordos com a gramática normativa em voga nos dias de hoje serão encontrados.

7 Empregamos o termo como forma de suscitar a violência que esse tipo de relação evoca. Mesmo que o "cliente" afirme que a relação de cunho sexual se deu de forma consensual mediante pagamento, a violência permanece, não necessariamente por ter sido física, mas por seu caráter econômico e simbólico.
} 
Com a pluralidade das identidades em sua obra, Pagu mostra que o burguês não é o único que explora sexualmente a mulher proletária. Foucault (1996) assevera que o poder atravessa grupos sociais; o poder não está nas mãos apenas de um grupo, mas se manifesta de diversas formas, em diversos grupos. Os homens proletários também exercem poder sobre as mulheres trabalhadoras quando se trata de gênero. Homens e mulheres do proletariado podem ser colegas de luta quando se trata de direitos trabalhistas - mesmo que a mulher necessite de direitos diferentes; porém, quando se trata de exploração sexual, o "coleguismo" da fábrica é deixado de lado. Isso é mostrado de forma breve por Pagu (1933, p. 66) quando um homem consome o serviço prestado pelas mulheres no prostíbulo, sem pensar no sofrimento dessas que lá estão por lhes ser sua única alternativa.

- Eu prefiro a corcunda porque ninguem quer. Essa ao menos é limpa!

Um operario loiro de vinte anos. Cabelos longos empastados na testa. A roupa remendada de cores diversas, conta os nikeis.

- Vae tudo no choque da materia! Quer uma cerveja, moça?

Novamente discutindo sobre o poder que atravessa grupos sociais, Patrícia Galvão não deixa de ressaltar acerca do poder que as mulheres burguesas detinham. Oliveira (2014), em seu artigo $A$ solitude feminista de Patrícia Galvão em Parque Industrial, explica que Pagu se indignava diante da luta de Bertha Lutz, que procurava o direito ao voto feminino - exceto para as mulheres não alfabetizadas. Para Pagu, o feminismo de Bertha Luz, que a própria Pagu demoninava de "feminismo pequeno-burguês" (OLIVEIRA, 2014, p. 222), excluía ao invés de incluir, pois defendia apenas os direitos que diziam respeito às mulheres ricas e burguesas, esquecendo-se das mulheres proletárias.

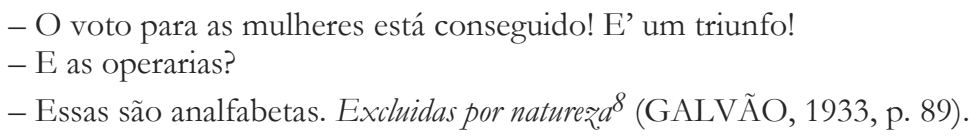

Oliveira (2014, p. 223) diz que Patrícia Galvão acabava se isolando dos movimentos feministas existentes no Brasil, pois ela era mais radical, mais revolucionária, querendo abarcar em sua luta o direito de todas as mulheres, observando suas necessidades de acordo com sua realidade, focando nas mulheres trabalhadoras:

Lutz queria utilizar o voto não só como instrumento, mas como um símbolo dos direitos de cidadania, e, sobretudo, como um meio de ação. Buscava o lado do movimento feminista que fosse individual, econômico e intelectual, classificando-o como mais avançado. O ponto de vista e o modo de ação em relação às mulheres brasileiras de um modo geral, utilizado por Bertha Lutz, incomodava sobremaneira Patrícia Galvão. Era como se essas posturas ferissem seus ideais comunistas. Nesse sentido, pode-se perceber que a preocupação de Bertha Lutz eram as mulheres intelectuais do país, e que a sua luta era pelos direitos de cidadania, enquanto que Galvão preocupava-se mais com as trabalhadoras e proletárias e sua luta era por melhores condições de trabalho, principalmente, com o fim da diferença de classes.

A autora do "romance proletário" também coloca mulheres burguesas como patroas que abusam do poder, adestrando suas proletárias por meio do medo. Medo do desemprego, medo da miséria, medo do poder... Mais uma vez, ela expõe que nem mesmo sendo mulheres, as mulheres da burguesia ligavam para a situação em que se encontravam as

\footnotetext{
${ }^{8}$ Grifo nosso. Fazemos esse destaque no intuito de evidenciar a forma como a burguesia via o proletariado, como se o analfabetismo e a exclusão social consequente fossem naturais e não o que são de fato, problemas sociais.
} 
trabalhadoras (GALVÃO, 1933, p. 15-16):

- O meu pijama é para amanhã. Vae ser um colosso de intimidade a minha festa! (...)

Uma menina pálida atende ao chamado e custa a dizer que é impossível terminar até o dia seguinte a encomenda.

- Que é isso? Exclama a costureira empurrando-a com o corpo para o interior da oficina. Você pensa que vou desgostar mademoiselle por causa de umas preguiçosas! Hoje haverá serão até uma hora.

- Eu não posso madame, ficar de noite! Mamãe está doente. Eu preciso dar o remedio pra ela!

- Você fica! Sua mãe não morre por esperar umas horas. (...) Se você for é de uma vez.

A proletaria volta para seu lugar entre as companheiras. Estremece á idéa de perder o emprego que lhe custara tanto arranjar.

Além dos desamparos já discutidos aqui, Pagu também critica o posicionamento do Estado diante da realidade feminino-proletária. As mulheres proletárias não são educadas sexualmente e, em consequência, não têm condições de cuidar de seus filhos que são resultado de gravidez indesejada. Além da necessidade de educação sexual, Oliveira (2014, p. 225) coloca que as mães precisam trabalhar para dar o mínimo suporte financeiro para suas crianças. Todavia, o Estado novamente ignorava a realidade dessas mulheres, que precisavam trabalhar, mas não tinham onde deixar seus filhos.

- Gente pobre não devia ter filho!

- Ahi vem a Didi! Voce viu a creança dela, que mirrada!

Uma preta deformada aparece com o filho cinzentinho. Uma teta escorrega da boquinha fraca, murcha, sem leite. O avental encarvoado enxuga os olhinhos remelentos.

- Gente pobre não pode nem ser mãe! Me fizeram esse filho num sei como! Tenho que dar ele pra alguem, pro coitado não morrer de fome. Se eu ficar tratando dele como é que arranjo emprego? Tenho que largar dele pra tomar conta dos filhos dos outro! Vou nanar os filhos dos rico e o meu fica ahi num sei como.

Ninguem diz nada. Estão quasi todas nas mesmas condições.

Passam a falar na sedução das garotas do bairro.

- Uma que se perde logo é a Julinha. Magine que ela vae no armazem e deixa os rapazes fazerem assim nos peitinhos dela. Outro dia, até pegaram uma conversa. O Taliba estava na latrina e ouviu ela perguntar pro Pouca-Roupa se ele tinha enfiado tudo!

- Que diabo! As creanças tem mesmo que saber. Como é que a gente pode esconder se mora tudo no mesmo quarto? A gente tem que trocar roupa tudo junto. A gente tem que fazer tudo perto deles. Só rico que póde ter vergonha porque cada um tem o seu quarto (GALVÃO, 1933, p. 94-95).

Dentre tantas identidades femininas existentes em Parque Industrial, há também as mulheres que enxergam as questões manifestas em sua realidade e que até se revoltam contra a burguesia. Um dos expoentes dessa identidade feminina seria Otávia, que alerta Corina sobre a exploração sexual exercida pelo seu amado burguês: “- Corina, voce não percebe quem é o Arnaldo? Ele não passa de um horrivel burguez! Logo se saciará de voce! Eles são sempre assim..." (GALVÃO, 1933, p. 53). A personagem Matilde ilustra a exploração sexual e o abuso de poder dos homens burgueses sobre as mulheres proletárias existente no ambiente de trabalho, criando consciência ao contar para Otavia que foi demitida por se recusar a ir ao "quarto do chefe": "Como sinto, companheira, mais do que nunca a luta de classes! Como estou revoltada e feliz por ter consciencia! (...) E' impossível que os proletarios não se revoltem. Agora é que eu senti toda a injustiça, toda a iniquidade, toda a infamia do regime capitalista" (GALVÃO, 1933, p. 123-124). Outra dessas identidades femininas é corporificada na personagem Rosinha Lituana, estrangeira vinda da Lituânia que passa a vida sendo explorada pelo capitalismo e é presa por ajudar a organizar uma manifestação política dentro da fábrica, mostrando para as mulheres trabalhadoras que são importantes na luta pelos direitos de classe. 
- Camaradas! Não podemos ficar quietas no meio desta luta! Devemos estar ao lado dos nossos companheiros na rua, como estamos quando trabalhamos na fabrica. Temos que lutar juntos contra a burguezia que tira a nossa saude e nos transforma em trapos humanos! Tiram do nosso seio a ultima gota de leite que pertence a nossos filhinhos para viver no champanhe e no parasitismo!

(...) Camaradas! Formemos uma frente de ferro contra a barbaridade dos burgueses que já estão sentindo a agonia de seu regime e por isso apelam para as violencias e para o terror! Tenhamos confiança na vitoria proletaria! Lutemos pela greve e pela liberdade de nossos presos! Maridos, companheiros, irmãos e noivos! Pela greve geral! Contra a burguezia e seus lacaios armados! (GALVÃO, 1933, p. 103)

Em Parque Industrial, há mulheres que se tornam subordinadas por necessitarem do emprego, há mulheres que veem a real exploração por trás do salário dado como mérito de um trabalho exaustivo, há as que percebem que sua sexualidade é vista como objeto, há as que se perdem em um triste fim. Patrícia Galvão desenha perfis diversos, pois esses refletem a real vida de opressão das mulheres proletárias. O romance proletário de Pagu é de demasiada importância para a literatura brasileira que, apesar de dizer muito sobre o posicionamento político da autora, fala também acerca da sociedade da época e marca um período histórico de importantes transformações na sociedade brasileira.

\section{Corina: a representação da dor da mulher negra}

Sueli Carneiro, em entrevista concedida para a revista Cult (2017), fala sobre a ignorância da militância de esquerda acerca da questão racial. A filósofa lembra que raça e classe estão estritamente ligadas no Brasil, e que a esquerda esquece sobre raça ao falar da luta de classes, nublando um debate de grande importância. Essa é uma realidade que começa a mudar, para Carneiro, somente nos dias atuais com o auxílio da internet. Patrícia Galvão, mais uma vez indo de encontro ao comum, personaliza em sua narrativa a realidade invisibilizada da mulher negra e operária da época por meio de Corina, outra das mulheres do chão da fábrica.

A trajetória da personagem começa como a de todas: na fábrica, como operária, trabalhando. Também como todas, Corina tem em sua identidade um diferencial: a cor, evocada por seu nome. Muito apaixonada pelo "burguês da baratinha", durante o relacionamento ela se descobre grávida. Antes de contar ao seu amado sobre a gravidez, Corina pensa sobre o que vai fazer e lamenta sua cor, explicitando para o leitor a forma como ser negra é um desafio em uma sociedade racista.

Corina remenda, esforçando a vista.

Porque nascera mulata? E' tão bonita! Quando se pinta, então! O diabo é a côr! Porque essa diferença das outras! O filho era dele tambem. E se saisse assim, com a sua côr de rosa seca! Porque os pretos têm filhos? Xi! (...) Agora a creancinha que vae vir! Que tamanho estará agora? Já terá olhinhos? E a mãosinha? (GALVÃO, 1933, p. 49)

Assim como as mulheres proletárias precisavam de uma visão diferente acerca de sua realidade - visão que as feministas burguesas preferiam ignorar -, as mulheres negras e proletárias precisavam de uma visão triplamente diferente que considerasse as questões de gênero, raça e classe, tudo junto.

Discutindo sobre a subalternização da mulher negra e expondo a forma como a sociedade a enxerga, Bell Hooks (1995, p. 468) explica que "o sexismo e o racismo, atuando juntos, perpetuam uma iconografia de representação da negra que imprime na consciência cultural coletiva a ideia de que ela está neste planeta principalmente para servir aos outros". 
Pagu acusa a permanência desse pensamento em Parque Industrial, pois, mesmo que as mulheres proletárias fossem lembradas pelo feminismo pequeno-burguês (ainda que de forma preconceituosa), a questão racial não era considerada nessa lembrança dado o caráter de subalternização que lhe era ulterior.

Sueli Carneiro (CULT, 2017) defende que "ser mulher negra coloca outras contradições, outras necessidades e outras demandas que o feminismo teria que incorporar se quisesse $e^{9}$ representar as necessidades e os interesses do conjunto das mulheres brasileiras". Em concordância, Bell Hooks (2000, p. 40) afirma que mesmo com um conhecimento acerca da necessidade de recorte na militância feminista, "muitas mulheres brancas privilegiadas continuaram agindo como se o feminismo as pertencesse, como se elas estivessem no comando"10.

Mais uma vez destacando a forma como Pagu retrata as relações de poder que se atravessam, há um momento da obra em que a família de Eleonora é descrita; família proletária, pais trabalhadores que sempre quiseram o melhor para sua filha. Família oprimida na relação de classes, mas tem uma "preta" ajudando no "serviço da casa" (GALVÃO, 1933, p. 35), de uma forma que manifesta a simbólica que cristaliza uma reverberação do discurso que torna distinta, em dois polos antagônicos, a representação daquilo que viria a ser chamado de casa grande e de senzala.

Patrícia Galvão se apropria de um discurso racista que está sempre destacando a cor negra de forma negativa, utilizando termos pejorativos para se referir a Corina e a outras mulheres negras que passam pela obra. Ao ser descrita, Corina é intitulada "a mulata do ateliê" (GALVÃO, 1933, p. 16), enquanto as outras mulheres descritas no mesmo parágrafo são apenas trabalhadoras ou gananciosas. Pagu, entretanto, faz isso de propósito: a autora utiliza esse discurso como forma de denúncia, mostrando a exclusão sofrida por essas mulheres em diversos espaços - desde a fábrica até a periferia em que elas moram, denunciando a marginalização simbólica e espacial destas. A forma como a autora descreve Corina e os diversos outros momentos em que as palavras "preta" e "mulata" são utilizadas podem incomodar o leitor, mas foram necessárias para expor de que forma o racismo estava presente e enraizado no contexto da narrativa.

Outra estratégia da escritora para criticar o sistema é a própria estrutura de sua narrativa. Apropriando-se da velocidade excessiva exigida pela indústria e da necessidade de cada trabalhador fazer uma pequena parte de um todo milhares de vezes por dia, ela constrói uma estrutura fragmentária que representa os aspectos de instantaneidade e de produção em massa exigidos pelo mundo moderno que tanto crítica.

\section{Conclusão}

Ao fim deste estudo, não há dúvidas de que o romance proletário de Patrícia Galvão é a prova de que a literatura pode ser atemporal. Apesar de ter sido escrito durante o Modernismo brasileiro e, além disso, ser sobre o período da modernidade, Parque Industrial consegue expor as questões que envolvem a existência - e a resistência - das mulheres brasileiras até os dias atuais. Essa obra não é apenas importante para o estudo da literatura brasileira de modo histórico, mas para que se observe como a realidade descrita e criticada por Pagu em sua narrativa ainda existe na contemporaneidade, fazendo-nos - pesquisadores, leitores,

\footnotetext{
${ }^{9}$ Grifo nosso.

10 Tradução nossa, sendo o trecho original: "many privileged white women continued to act as though feminism belonged to them, as though they were in charge".
} 
militantes, pessoas - refletir acerca de como as problemáticas discutidas na obra ainda se fazem presentes na sociedade - e, o mais importante, como ainda precisam ser discutidas e combatidas.

\section{Referências}

BEAUVOIR, Simone de. O segundo sexo: fatos e mitos. Difusão Europeia do Livro: São Paulo, 1970.

FOUCAULT, Michel. A ordem do discurso. Aula inaugural no College d'e France, pronunciada em 2 de dezembro de 1970. Edições Loyola: São Paulo, 1996.

DALCASTAGNÈ, Regina. Literatura Brasileira Contemporânea - Um Território Contestado. Editora Horizonte: São Paulo, 2012.

GALVÃO, Patrícia. Parque Industrial. São Paulo: Alternativa, 1933.

HOOKS, Bell. Intelectuais negras. Revista Estudos Feministas. Volume 3, no 2, 1995. Disponível em <https://periodicos.ufsc.br/ index.php/ref/article/view/16465>. Acesso em 17 de março de 2019.

HOOKS, Bell. Feminism is for everybody: passionate politics. Cambridge: South End Press, 2000.

MORAES, Letícia Nunes de. Mulher, raça e classe em Patrícia Galvão e Angela Davis. São Paulo: UFSCar, 2017. Disponível em

<http://www.encontro2018.historiaoral.org.br/resources/anais/8/1524246847_AR-

QUIVO_Texto_completo-ST01-LeticiaNunesdeMorae s.pdf>. Acesso em 24 de maio de 2018.

OLIVEIRA, Carmen Sílvia Araújo de. A Solitude Feminista de Patrícia Galvão em Parque Industrial. Miguilim: revista eletrônica do Netlli. Volume 3, no 2. Maio - agosto, 2014. Disponível em

<http://periodicos.urca.br/ojs/index.php/MigREN/article/view/718/694>. Acesso em 03 de junho de 2018.

PERROT, Michelle. Minha história das mulheres. São Paulo: Contexto, 2007.

SANTOS, Glauce Souza. Parque Industrial: acontecimento e descontinuidade. IN: SILVA, Natali F. da Costa; CRUZ, Lua Gill da; TATIM, Janaína; PEREIRA, Marcos Paulo T (orgs). Mulheres e a Literatura brasileira. Macapá: Unifap, 2017.

SPIVAK, Gayatri C. Pode o subalterno falar? Belo Horizonte: Contexto, 2010. 